\title{
Políticas públicas e formação docente: a possibilidade da investigação didática no Programa Bolsa Alfabetização
}

\section{Luci Ana Santos da Cunha ${ }^{1}$}

Resumo: $O$ artigo realiza análise preliminar sobre as contribuições do Programa Bolsa Alfabetização tanto na formação inicial de professores para as séries iniciais do ensino fundamental $\left(1^{\circ}\right.$ ao $5^{\circ}$ ano) nas Instituições de Ensino Superior (Pedagogia), quanto na colaboração da construção do sistema alfabético e da competência leitora e escritora dos alunos das escolas públicas da cidade de São Paulo.

Palavras-chave: formação de professores; investigação didática; política educacional.

Abstract: The article realize preliminary analysis about the contributions of the Literacy Grant Program, both in initial teacher training to the grades of elementary school (1 st to 5th grade) in institutions of higher education (Pedagogy), as well in the collaboration on the construction of the alphabetic system and in student writer and reader competence of public schools in the city of São Paulo.

Keywords: teacher training; didactic research; educational policy.

“A prática docente crítica, implicante do pensar certo, envolve o movimento dinâmico, dialético, entre o fazer e o pensar sobre o fazer”.

Paulo Freire. Pedagogia da Autonomia

\footnotetext{
${ }^{1}$ Luci Ana Santos da Cunha é Pedagoga e Mestre em Didática: Metodologia e Teorias do Ensino pela FEUSP. É coordenadora dos curso de Pedagogia desde 2011 e da Pós-Graduação nas Faculdades Integradas Campos Salles desde 2007. É supervisora escolar da Prefeitura de São Paulo desde 20002. Publicou políticas públicas e formação docente na Revista Internacional d'Humanitats, v. 24, p. 29-32, 2012. Letramento e leitura de mundo: a formação de professores alfabetizadores. Filosofia e Educação - Interfaces com Lauand, Jean (org.) e Formação docente: pensando o estágio supervisionado - Breve Histórico e Filosofia e Educação. São Paulo: FACTASH Ed., p. 83-94, 2011.
} 
A formação docente e a possibilidade da investigação didática no Programa da Bolsa Alfabetização

Considerando a realidade de nossas escolas públicas em nosso país, especialmente quanto aos anos iniciais do ensino fundamental (ciclo $I, 1^{a}$ ao $5^{a}$ ano), em que, se aumentou a possibilidade de inclusão numérica de alunos, ainda encontramos muitas dificuldades em relação a inclusão social e o ensino que garanta a formação de leitores e escritores competentes.

Deparamo-nos com alunos apresentando muitas dificuldades de aprendizagem (notadamente leitura e escrita) e indisciplina, geradas por vários fatores, que acabam por transformar o professor em um profissional desmotivado e estressado.

Desta forma, para expiar a sua responsabilidade, os professores ora culpam os alunos e as famílias que não acompanham os estudos, ora culpam o sistema de aprendizagem em ciclos (que estão denominando "promoção automática"), que não "reprova" mais o aluno.

Muitos equívocos são cometidos e as distorções são percebidas nas falas de alguns professores: "Se o aluno vai passar de ano mesmo, eu ensino, mas quem aprendeu, aprendeu. Quem não aprendeu passa do mesmo jeito, por que eu vou insistir?"; "O aluno sabe que vai passar, por isso não estuda"; "Se eu não posso reprovar, para que dar provas?"; "Agora os alunos não nos respeitam mais. Não podemos falar que vamos diminuir as notas e reprová-los. Eles sabem que vão passar"; "Nas escolas particulares não tem isso não! Isto é coisa de escola de pobre".

Muitas destas falas expressam a falta de entendimento do processo de aprendizagem em ciclos, mas não se pode negar e falsear o sentido e a forma de implantação desta política educacional em nosso país. O que temos vivido no sistema público de ensino de São Paulo é o estrangulamento nos finais do ciclo, onde um número muito expressivo de alunos é retido, ou, se não são reprovados, tornam-se analfabetos funcionais.

Essa insegurança, desmotivação e resistência de muitos professores, relacionam-se também, muitas vezes, a precariedade da sua formação inicial e o mesmo não possuir os saberes necessários para trabalhar com as dificuldades de leitura e escrita, que seus alunos apresentam.

Visando atender a essas demandas, a Secretaria da Educação do Estado de São Paulo criou o Programa Ler e Escrever, que tem como principal meta alfabetizar todos os alunos da rede Estadual de Ensino. Várias ações foram propostas para se atingir tal meta. Entre elas, está o Programa Bolsa Alfabetização, um programa articulado ao Ler e Escrever que possibilita a entrada do aluno universitário, estudante dos cursos de Letras e Pedagogia, na sala de aula dos $2^{\circ} \mathrm{s}$ anos, como um colaborador do professor na tarefa de ensinar a ler e escrever convencionalmente todos os alunos da rede pública estadual dos $2^{\circ} \mathrm{s}$ anos.

Neste Programa, o aluno universitário, denominado alunopesquisador (AP), deverá fazer uma exploração didática na sala de aula em que estiver atuando, para acompanhar o avanço dos alunos na leitura e na escrita, observando e registrando as atividades didáticas desenvolvidas em aula, aprofundando estes procedimentos com estudos teóricos e práticos sobre os temas desenvolvidos.

Segundo os documentos oficiais do Programa, "a articulação entre o Bolsa Alfabetização e o Ler e Escrever se dá pela formação continuada da equipe técnica da escola e pelos encontros mensais com os professores-orientadores (POs) e interlocutores das Instituições de Ensino Superior (IES). O programa se pauta por uma cultura de comprometimento e de responsabilidade para que tenha o sucesso almejado na sua implantação" (FDE, 2010). Consta ainda, dos documentos oficiais, que os objetivos do Programa são: Aprimorar a formação inicial dos alunos estudantes dos cursos de Pedagogia e Letras, possibilitandolhes atuar como docentes da rede pública de 
ensino com conhecimento de sua realidade; Possibilitar o acesso à leitura e à escrita a todos os alunos de $2^{\circ}$ ano; Comprometer as IES com causa do ensino público.

Quanto a Pesquisa de Investigação Didática, ela é realizada pelo alunopesquisador e, sob o acompanhamento do professor-orientador da Instituição de Ensino Superior, que realiza o projeto de pesquisa como uma modalidade de investigação didática, realizada nas classes de $2^{\circ} \mathrm{s}$ anos, convertida em registro escrito, com o objetivo de apresentar à escola e à IES, um estudo temático de alguns aspectos da alfabetização: leitura feita pelo professor; produção oral com destino escrito; cópia e ditado (ressignificação da cópia); rotina de leitura e de escrita.

E, nesta perspectiva, alterou-se o enfoque sobre a formação de professores, pois a universidade deixou de ser a produtora de pacotes comercializáveis para o consumo das escolas. Por ser um processo, permitiu ao AP (aluno pesquisador) a segurança, o apoio necessário para que ele fosse se constituindo, se descobrindo, construindo novos saberes e eliminando a ideia de considerar o saber um produto acabado.

Para que isso pudesse ser realizado, a reflexão precisou ser institucional, com espaço e tempo garantidos, de modo que a prática fosse revista sob fundamentação teórica. Neste sentido, as reuniões semanais realizadas nas IES com os alunos pesquisadores buscam criar situações didáticas em que teoria e prática se engendram, visando a reflexão e a construção de boas situações didáticas de aprendizagem.

Neste enfoque, o papel da teoria se tornou importante para que não fossem empreendidas ações pautadas apenas no senso comum, mas que ampliassem perspectivas de inovações, como respostas para as situações problemas que surgissem.

Segundo Aratangy (2011), é possível constatar, nas escolas públicas da rede estadual de ensino, que a qualidade de ensino melhorou e que os alunos do ciclo I $\left(1^{\circ}\right.$ ao $5^{\circ}$ ano) tornaram-se mais interessados em aprender a ler e escrever e que, segundo os dados do SARESP 2009, 86\% dos professores que receberam alunos pesquisadores afirma que os mesmos contribuem com o processo de alfabetização e na avaliação realizada com pais de alunos do Ciclo I, em 2010, é relatado que os pais atribuíram nota 8,7 para o Programa Bolsa Alfabetização e nota 8,5 para o trabalho conjunto professor/aluno pesquisador.

O Programa Bolsa Alfabetização, que atende atualmente no Estado de São Paulo 2.080 alunos, 67 Instituições de Ensino Superior , 650 escolas da capital e 300 do interior (Aratangy,2011), tem como marco importante a reflexão e aprofundamento dos fundamentos teóricos e práticos, engendrando e articulando ações fecundas de aprendizagem entre todos os envolvidos e particularmente, do futuro professor, aluno pesquisador em processo de formação.

A identidade docente dos APS também vai se constituindo com o enfrentamento de problemas que a ação em campo apresenta. Afinal, as discussões que ocorrem não são sobre de problemas de uma escola virtual, por simulação. Os problemas são reais, os alunos também (seus sonhos, seus medos, suas expectativas, suas alegrias, tristezas, dificuldades de aprendizagem).

Ao destacar as contribuições que o estágio supervisionado realizado através do Programa Bolsa Alfabetização pode trazer para a formação do bom professor, queremos focalizar um aspecto de um todo maior, que é o próprio curso de formação e seu currículo. Os responsáveis pelos cursos de formação inicial de professores precisam preocupar-se em construir uma prática reflexiva que seja inerente à identidade profissional. Esta preocupação deve estender-se também à formação continuada, responsabilidade de cada elemento que compõe a unidade escolar: professores, coordenadores pedagógicos, diretores, supervisores, orientadores técnicos educacionais, enfim, de todos que enquanto corpo da escola - estarão 
recebendo e colaborando com a formação dos alunos pesquisadores.

Aprender fazendo, tornando inseparáveis o saber, o real vivido e, inserido neste contexto, as reflexões engendradas através do estágio realizado no Programa Bolsa Alfabetização, possibilitando o diálogo polifônico com tantas realidades, tantas crianças, tantos educadores. Onde professores universitários e professores das escolas públicas, com diferentes formações, puderam contribuir para o pensar, o refletir de modo aprofundado sobre como se pensa e se faz educação, qual a qualidade de professor estávamos sendo e qual a qualidade de professor precisávamos ser. Qual a qualidade de professor estávamos formando e qual qualidade de professor precisávamos formar.

E assim, toda esta trajetória tem redimensionado a formação dos alunos pesquisadores, pois aprendem a valorizar os espaços coletivos, a fazer destes espaços um momento de construção pedagógica, a trabalhar com a investigação didática. Valorizando os saberes construídos pelos professores em seu local de trabalho, motivando-os a serem leitores e pesquisadores e a valorizar o processo de formação, como nos coloca Paulo Freire:

Por isso, é fundamental que, na prática da formação docente, o aprendiz de educador assuma que o indispensável pensar certo não é presente dos deuses nem se acha nos guias de professores que iluminados intelectuais escrevem desde o centro do poder, mas pelo contrário, o pensar certo que supera $O$ ingênuo tem que ser produzido pelo próprio aprendiz em comunhão com o professor formador. (Freire, 1997, p.43).

\section{Referencias bibliograficas}

ALARCÃO, Isabel. Ser professor reflexivo. - Formaşão reflexiva de professores.

Estratégias de Supervisão. Porto, Porto Editora.1996.
ARATANGY, Claudia. Colóquio com as Universidades Parceiras do Bolsa Alfabetização.Palestra proferida no auditório da Secretaria Estadual de Educação de São Paulo em 15 / dez / 2011.

CANDAU, Vera M.F., LELIS, Isabel.A. A relação teoriaprática na formaça do educador. Tecnologia Educacional. Revista da Associação Brasileira de Tecnologia Educacional. Rio de Janeiro, 1983, v12 p.55.

CONTRERAS, José. La autonomia del profesorado. Madrid: Ed. Morata. 1997.

CUNHA, Luci Ana S. Estágio supervisionado e a formação de professores. 4 a 8 de maio de 1998. Águas de Lindóia, SP. Anais do IX ENDIPE (Encontro Nacional de Didática e Prática de Ensino) Águas de Lindóia, SP: 1998.

FDE. Apresentação do Programa Bolsa Alfabetização.Acessado em 10/04/2012 no sítio http://lereescrever.fde.sp.gov.br.

FIORENTINI, GERALDI \& PEREIRA, Refletindo com Zeichner: um encontro orientado por preocupações politicas, teóricas e epistemológicas. In: Cartografias do trabalho docente. Campinas: Mercado de Letras, 1998

FREIRE, Paulo. A Educação na cidade. São Paulo: Cortez, 1991.

Pedagogia da autonomia. Saberes necessários à prática educativa. Rio de Janeiro: Paz e Terra, 1997.

FUSARI, José C. A formação contínua de professores: o papel do Estado, da universidade e do sindicato. In: SMELIAN, A. (org.) Olhando a qualidade do ensino a partir da sala de aula. IX ENCONTRO NACIONAL DE DIDÁTICA E PRÁTICA DE ENSINO. Águas de Lindóia (SP),1998.

KINCHELOE, Joe. A formação do professor como compromisso político: mapeando o pósmoderno. Porto Alegre: Artes Médicas, 1997.

NÓVOA, A. Os professores e a sua formação. Lisboa: Dom Quixote. 1992.

Espaços de Educação e Tempos de Formação. Conferência realizada na Fundação Calouste Gulbenkian, 2001. Acessado em 20 / out /11 no sítio

http://www.gulbenkian.pt/acarte/conferencia.h tml

RIOS, Terezinha A . Ética e competência . São Paulo: Cortez, 1997.

, Compreender e ensinar: Por uma docência da melhor qualidade. São Paulo: Cortez, 2001.

SACRISTÁN, José G. Consciência e ação sobre a prática como libertação profissional dos professores. In: NÓVOA, A .(org.). Profissão Professor. Porto: Ed. Porto, 1991. 
Poderes instáveis em Educação. Porto Alegre: Artes Médicas, 1999.

SCHÖN, D. Formar professores como profissionais reflexivos. In: Nóvoa, A (org.) .et alii. Os professores e a sua formação. Lisboa: Dom Quixote, 1995.

SOARES, Magda. Letramento: um tema em três gêneros. Belo Horizonte: Autêntica, 1998.

ZEICHNER. K.M. A formação reflexiva dos professores: idéias e práticas. Lisboa: Educa, 1993. 